Original research article

\title{
Phenolic profiles, antioxidant activity and minerals in leaves of different grapevine varieties grown in Serbia
}

\author{
Milica M. Pantelića ${ }^{a}$, Dragana Č. Dabić Zagorac ${ }^{a}$, Ivanka Ž. Ćirića ${ }^{\mathrm{a}}$, Marija V. Pergal ${ }^{\mathrm{b}}$, \\ Dubravka J. Relićc , Slavica R. Todićc ${ }^{\mathrm{d}}$, Maja M. Natićc,* \\ a Innovation Center, Faculty of Chemistry Ltd, University of Belgrade, 11158 Belgrade, Serbia \\ b Institute of Chemistry, Technology and Metallurgy, University of Belgrade, 11000 Belgrade, Serbia \\ ${ }^{c}$ Faculty of Chemistry, University of Belgrade, P. O. Box 51, 11158 Belgrade, Serbia \\ d Faculty of Agriculture, University of Belgrade, Nemanjina 6, 11080 Zemun, Serbia
}

\section{A R T I C L E I N F O}

Chemical compounds studied in this article: Catechin (PubChem CID: 318242652) Ellagic acid (PubChem CID: 5281855)

Ferulic acid (PubChem CID: 445858)

Gallic acid (PubChem CID: 370)

Gallocatechin (PubChem CID: 9882981)

p-Hydroxybenzoic acid (PubChem CID: 135)

Rutin (PubChem CID: 5280805)

Keywords:

Leaves

Geographical origin

PCA

Polyphenols

Minerals

RSA

Food analysis

Food composition

\begin{abstract}
A B S T R A C T
This research was designed to determine phenolics content, radical scavenging activity and mineral composition of 22 grapevine leaves of diverse varietal origin. Samples were collected from two vineyards located in Central Serbia (Belgrade vineyard area) and Eastern Serbia (Mlava vineyard area). Leaf extracts were characterized mostly with phenolics acids, flavonols and flavan-3-ols. Ellagic acid and rutin were the most abundant components, found in the concentration up to $770 \mathrm{mg} / \mathrm{kg}$ and $450 \mathrm{mg} / \mathrm{kg}$ of dry weight, respectively. Total phenolic content was in the range from 27.5 to $76.0 \mathrm{~g}$ GAE $/ \mathrm{kg}$ of dry weight while the radical scavenging activity ranged from 0.429 to $0.867 \mathrm{mmol} \mathrm{TE} / \mathrm{kg}$ of dry weight. The most common element in all samples was $\mathrm{K}$ (content ranging from $2.30 \mathrm{~g} / \mathrm{kg}$ to $6.77 \mathrm{~g} / \mathrm{kg}$ of dry weight), followed by $\mathrm{Ca}, \mathrm{Na}$, and $\mathrm{B}$. A variation in the chemical composition was shown to be convenient way to differentiate among the grape leaves of diverse varietal origin. Clear separation was demonstrated between objects of different geographical origin by Principal Component Analysis. Serbian variety 'Petra', an interspecies hybrid with atypical composition, was detected as an outlier in comparison to other samples.
\end{abstract}

\section{Introduction}

With a long history of cultivation, consumption and trade, viticulture in Serbia is a very important branch of agriculture and has great economic significance. The most of the cultivation and the production of grapes is done by local wineries running small family business.

Beneficial effects of the consumption of grape and wine on human's health are well documented. Also, great interest for other edible plant parts of Vitis vinifera Linneo ( $V$. vinifera L.) species exists, as these are considered to be of high nutritional value. Potential bioactivities and medicinal properties have been ascribed to all plant parts, but especially to pomace, shoots, stems and leaves, which are used in the formulation of dietary antioxidant supplements (Dani et al., 2010; Handoussa et al., 2013; Schoedl et al., 2012). Additionally, grapevine leaves are characterized with a pleasing flavor and can be used as a fresh food, cooked, baked. It is also frequently found as a marketed food supplement. Chemical composition is highly influenced by the variety of $V$. vinifera L., degree of maturation, climate condition and the location in which the plants are grown (Krol et al., 2014; Taware et al., 2010; Teixeira et al., 2013; Cadot et al., 2011).

Numerous studies conducted on $V$. vinifera L. plant materials indicate their importance as a good source of minerals, organic acids (malic, oxalic, fumaric, ascorbic, citric, and tartaric acid), polyphenols, enzymes and other ingredients essential to human nutrition. Especially, phenolic nutraceuticals were suggested as effective antioxidants related to health promotion (Gioxari et al., 2016). Among polyphenols, the presence of phenolic acids, flavan-3-ols, flavonols, stilbens, tannins, and anthocyanins was proven (Garrido and Borges, 2013) and their analysis

Abbreviations: DAD, diode array detector; DPPH, 2,2-diphenyl-1-picrylhydrazyl; ICP-OES, inductively coupled plasma-optical emission spectrometry; PCA, Principal Component Analysis; RSA, radical scavenging activity; TPC, total phenolics content

* Corresponding author.

E-mail addresses: mmandic@chem.bg.ac.rs,mnatic@gmail.com (M.M. Natić). 
over the past three decades is well documented (Cacciola et al., 2016; Stalikas, 2007). The most common techniques for the analysis of phenolics combine chromatographic and spectral methods and these hyphenated techniques are commonly employed for the chemical characterization of various samples. Once established, characteristic phenolic profiles are further explored by multivariate methods (Bertacchini et al., 2013; Donno et al., 2015, 2016), which are proven to be powerful tools for complex data exploration.

Development and optimization of LC MS/MS method for the quantification of polyphenols in $V$. vinifera $L$. leaves was the aim of the study of Schoedl et al. (2011). Furthermore, identification of these phytochemicals in growing grapevine leaves was done in order to define optimal harvest dates and leaf sampling position for maximum polyphenol contents (Schoedl et al., 2012). Studies on the alterations in phenolic profile and antioxidative activity of $V$. vinifera $\mathrm{L}$. leaves due to variety, picking-time, (Katalinić et al., 2009, 2013), drought stress (Krol et al., 2014), and powdery mildew infection (Taware et al., 2010) were also reported.

Various factors are recognized to cause variations in the elemental composition, such as soil type, usage of fertilizers, climate, irrigation practice, stage of plant maturity and different varieties of the same species (Ibrahim et al., 2012; Kabata-Pendias, 2011; Likar et al., 2015). Due to possible interrelation of some of these factors and the complex chemical interaction that can occur among minerals and other plant constituents, interpretation of the results of element profile of plants is difficult. The study reported by Cugnetto et al. (2014) showed that multivariate statistical analysis of the mineral composition of $V$. vinifera L. leaves could be a useful method for classification of the samples based on geographical origin, even when the geological background was similar.

Bearing in mind that leaves are traditionally used as food in human diet, it is of utmost importance to screen mineral composition, especially if the leaves are used as a supplement. Studying the presence of phenolic compounds and minerals of grapevine leaves as unutilized byproducts is considered to be valuable in terms of economic usage. Apart from a nutritional point of view, these parameters could be useful in determining the origin of the sample, as well as for adulteration and traceability studies.

Considering the lack of such studies in Serbia, we have designed this research in several directions: $i$ ) to collect grapevine leaves of different grapevine varieties from two vineyards, $i$ ) to characterize and identify the main phenolic compounds, total phenolics content (TPC) and radical scavenging activity (RSA), iii) to estimate mineral composition of the samples, $i v$ ) to evaluate the relation of leaf origin and its chemical composition, and $v$ ) to assess a value of these extracts as raw waste materials that could be used for various purposes.

To this end, samples belonging to two different vine-growing areas in Serbia were studied, in central part of Serbia and in the easternmost part of Serbia. Identification of specific polyphenols in the extracts was accomplished by liquid chromatography with mass spectrometry (UHPLC-DAD MS/MS). Mineral concentrations were established by inductively coupled plasma optical emission spectrometry (ICP-OES). TPC was measured using the standard spectrophotometric method with Folin-Ciocalteu reagent. To assess the possible antioxidant potential of the leaf extracts DPPH assay was done. Finally, the relation of leaf origin and its chemical composition was studied using the multivariate statistical procedure, Principal Component Analysis (PCA).

\section{Materials and methods}

\subsection{Chemicals}

Standards (HPLC-grade, $\geq 98 \%$ ) of quercetin (QUE), kaempferol (KAE), rutin (RUT), catechin (C), epicatechin (EC), gallocatechin gallate (GCG), epigallocatechin gallate (EGCG), gallocatechin (GC), epigallocatechin (EGC), trans-resveratrol (RES), aesculin (ASC), and phenolic acids (gallic (GaA), protocatechuic (PrA), p-hydroxybenzoic (HbA), gentisic (GeA), ellagic (ElA), chlorogenic (ChA), caffeic (CaA), pcoumaric (CoA), and ferulic acids (FeA), as well as Trolox were purchased from Sigma-Aldrich (Steinheim, Germany). 2, 2-diphenyl1-picrylhydrazyl (DPPH) was obtained from Fluka AG (Buch, Switzerland). Folin-Ciocalteu reagent, acetonitrile (MS grade), formic acid (MS grade), methanol (HPLC grade), sodium carbonate, nitric acid, and hydrogen peroxide, were obtained from Merck (Darmstadt, Germany). Standard solutions and dilutions were prepared using ultrapure water (TKA Germany MicroPure water purification system, $0.055 \mu \mathrm{S} / \mathrm{cm}$ ). Syringe filters $(13 \mathrm{~mm}$, PTFE membrane $0.45 \mu \mathrm{m}$ ) were purchased from Supelco (Bellefonte, PA, USA).

\subsection{Plant material}

Some of the well known international white and red wine grapevine varieties were studied 'Cabernet Sauvignon' (CSa), 'Merlot' (Mer), 'Cabernet Franc' (CFr), 'Sangiovese' (San), 'Shiraz' (Shi), 'Pinot Noir' (PNo), 'Gamay' (Gam), 'Riesling' (Rie), 'Sauvignon Blanc' (SBl), 'Welschriesling' (Wel), 'Pinot Gris' (PGr), 'Chardonnay' (Cha), 'Pinot Blank' (PBl), 'Vranac' (Vra), 'Muscat Hamburg' (MHa), 'Župljanka' (Žup), 'Chasselas musque' (Cmu), 'Beogradska besemena' (Bbe), together with Serbian autochthonous varieties 'Prokupac' (Pro), 'Plovdina' (Plo), and 'Smederevka' (Sme). Finaly, this study included one Serbian variety 'Petra' (Pet), which is an interspecies hybrid ('Kunbarat' $\mathrm{x}$ 'Pinot Noir' cross) whose parentage includes $12.5 \%$ of Vitis amurensis Ruprecht and $87.5 \%$ of Vitisvinifera Linneo.

A total of 22 grapevine leaf samples were collected in two different regions in Serbia (15 samples from Belgrade vineyard area (Central Serbia, $44^{\circ} 45^{\prime} 24.66^{\prime \prime} \mathrm{N}-20^{\circ} 34^{\prime} 54.50^{\prime \prime}$ E; elevation $153 \mathrm{~m}$ a. s. l) and

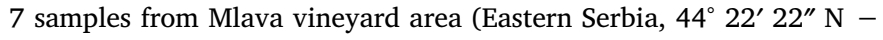
$21^{\circ} 25^{\prime} 05^{\prime \prime} \mathrm{E}$; elevation $348 \mathrm{~m}$ a. s. 1.), with different edaphoclimatic conditions.

Both regions are characterized as a Maritime Temperate or $\mathrm{Cfb}$ climate (Kottek et al., 2006). Average growing season (AWG) temperatures are $17.1{ }^{\circ} \mathrm{C}$ (Radmilovac) and $17.4^{\circ} \mathrm{C}$ (Mlava). Mean annual temperature respectively equals $11.5^{\circ} \mathrm{C}$ (Radmilovac) and $11.6{ }^{\circ} \mathrm{C}$ (Mlava), while the mean annual precipitation amounts are $665 \mathrm{~mm}$ (Radmilovac) and $693 \mathrm{~mm}$ (Mlava). The soil in the Radmilovac location is a deep, loamy Eutric Cambisol with the following structure: $41.4 \%$ clay, $56.1 \%$ silt, $2.5 \%$ sand, and with $2.1 \%$ of organic matter. The soil $\mathrm{pH}$ is slightly acidic ( $\mathrm{pH}$ 6.5) and it is somewhat low in phosphorus (8.7 $\mathrm{mg} \mathrm{P}_{2} \mathrm{O}_{5} / 100 \mathrm{~g}$ ) and potassium $\left(14.2 \mathrm{mg} \mathrm{K} \mathrm{K}_{2} \mathrm{O} / \mathrm{kg}\right.$ ). The soil in the Mlava vineyard area is Eutric Cambisol with $51.5 \%$ silt, $46.5 \%$ clay, $1.8 \%$ sand and with $1.9 \%$ of organic matter. It is noncarbonate and acidic ( $\mathrm{pH}$ 5.06). It is very poor in available phosphorus $\left(0.3 \mathrm{mg} \mathrm{P}_{2} \mathrm{O}_{5} /\right.$ $100 \mathrm{~g}$ ) and low in Potassium ( $8.9 \mathrm{mg} \mathrm{K}_{2} \mathrm{O} / 100 \mathrm{~g}$ ). In both Radmilovac and Mlava vineyard areas the soil's $\mathrm{C} / \mathrm{N}$ ratio is under 10 (8.9:1 and 9.4:1, respectively), which indicates favourable mineralisation of soil organic matter in their prevailing ecological conditions.

Healthy, green grapevine leaves were collected from five individual plants of each variety during the full ripening stage of the grape (September/October 2012). Leaves were authenticated in the field by the authors, and plant material was deposited at herbarium at the Faculty of Agriculture, University of Belgrade, Serbia. Samples were washed with water and dried (on air, in the dark, at room temperature) for twenty days. After removal of petioles, dry leaf samples were pooled and ground into a powder.

\subsection{Preparation of grapevine leaf extracts}

Extraction of polyphenols compounds from grapevine leaves was performed using the procedure described by Pantelić et al. (2016), with some modification. Pulverized and homogenized leaf samples (mass range 2.0001-2.0785 g) were extracted with $50 \mathrm{~mL} \mathrm{MeOH} / \mathrm{H}_{2} \mathrm{O}(70: 30$, $\mathrm{v} / \mathrm{v}$ ) solution containing $0.1 \% \mathrm{HCl}$, immersed in an ultrasonic bath 


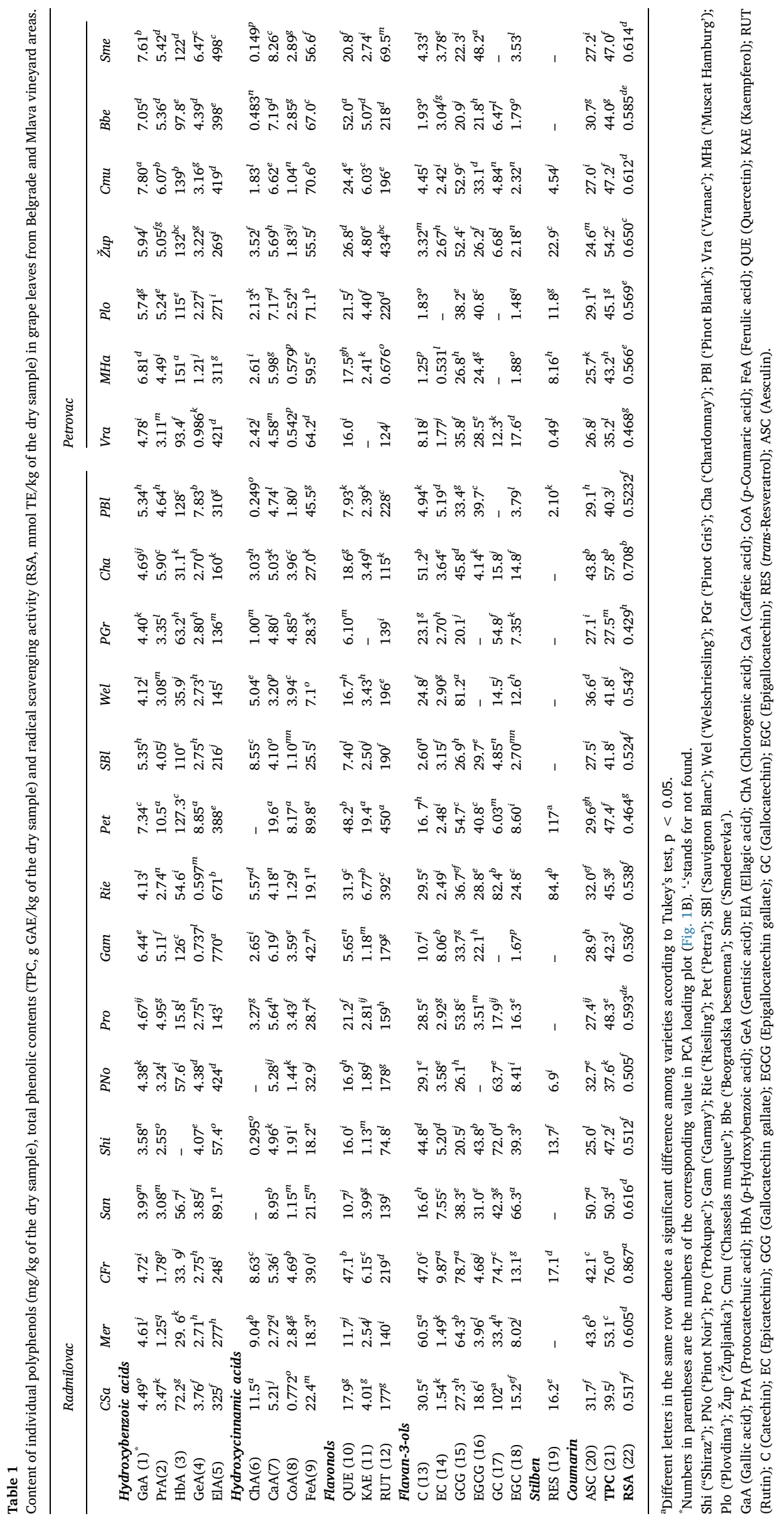


during $60 \mathrm{~min}$ (at room temperature, in shade). The extracts were then filtered using gauze and all procedure was repeated two more times. At the end, all supernatants (from 3 extractions) were merged into one total extract, which was then evaporated (at $40{ }^{\circ} \mathrm{C}$ ) on a vacuum evaporator (IKA RV 8) to dryness. The residues were dissolved in a mixture of $\mathrm{MeOH} / \mathrm{H}_{2} \mathrm{O}(60: 40, \mathrm{v} / \mathrm{v})$ to $c a .50 \mathrm{~mL}$, and before the analysis they were filtered through a $0.45 \mu \mathrm{m}$ membrane filter. These extracts were used for the determination of TPC, RSA and individual polyphenols.

\subsection{Determination of TPC and RSA}

TPC and RSA were determined spectrophotometrically on a Cintra 6 UV-vis spectrometer (GBC Scientific Equipment Ltd.). Before the analysis, all the extracts were appropriately diluted. Folin-Ciocalteu reagent was used to determine TPC in leaf samples, while a method based on the reduction of DPPH reagent was used to determine RSA of the leaves. Both procedures were described in Pantelić et al. (2016). The results for TPC were expressed as grams of gallic acid equivalent per kilogram of dry weight ( $\mathrm{g} \mathrm{GAE} / \mathrm{kg} \mathrm{DW}$ ) of samples and for RSA as milimoles of Trolox equivalents per kilogram of dry weight (mmol TE/ $\mathrm{kg}$ DW) of samples.

\subsection{Quantification of the phenolic compounds using UHPLC-DAD MS/MS}

Ultra-high performance liquid chromatography (Dionex Ultimate 3000 UHPLC with a diode array detector (DAD)) with a mass spectrometer (TSQ Quantum Access Max triple-quadrupole with heated electrospray ionization (HESI) (ThermoFisher Scientific, Basel, Switzerland)) was used for separation and quantification of polyphenols. The column used for analytical separation was a Syncronis C18 (ThermoFisher Scientific, Bremen, Germany). Aqueous formic acid solution $0.1 \%$ (A) and acetonitrile $100 \%$ (B) were the components of the mobile phase used for gradient elution (Natić et al., 2015). The flow rate was $0.4 \mathrm{~mL} / \mathrm{min}$ and the following gradient was utilized: 0.0-2.0 min $5 \%$ B, $2.0-12.0 \mathrm{~min}$ from $5 \%$ to $95 \%$ (B), $12.0-12.1 \mathrm{~min}$ from $95 \%$ to $5 \%$ (B), then $5 \%$ (B) for $3 \mathrm{~min}$. Each phenolic compound was quantitated by direct comparison with commercially available standards and the results were expressed as $\mathrm{mg} / \mathrm{kg}$ of dry leaf samples.

\subsection{Determination of mineral composition}

About $0.75 \mathrm{~g}$ of dried leaf samples were digested at $200{ }^{\circ} \mathrm{C}$ for $20 \mathrm{~min}$ in a microwave digestion vessel system ETHOS 1 (Milestone, Italy), using a mixture of $65 \%$ nitric acid and $30 \%$ hydrogen peroxide $(10: 2, \mathrm{v} / \mathrm{v})$. After cooling to room temperature, the solution was transferred into a clean volumetric flask and diluted to $25 \mathrm{~mL}$ with ultrapure water.

The content of mineral elements in solution samples was determined by ICP-OES using spectrometer Thermo Scientific iCAP 6500 Duo ICP (Thermo Fisher Scientific, Cambridge, United Kingdom). Standards for the instrument calibration were prepared on the basis of multi-elements certified reference solution ICP Standards: SS-Low Level Elements ICV Stock and ILM 05.2 ICS Stock 1 (VHG Labs, Inc- Part of LGC Standards, Manchester, NH 03103 USA) and Multi-Element Plasma Standard Solution 4, Specpure (Alfa Aesar GmbH and Co KG, Germany).

The grapevine leaves standard reference material (SRM 1573a; National Institute of Standard and Technology, NIST, Gaithersburg, MD 20899, USA) was digested in triplicate and analyzed to support quality assurance and control. The analytical process quality control indicated that the recovery concentrations were within 96-103\%. Precision of the procedure was determined as the relative standard deviation (RSD) for three measurements. Results showed that the RSDs were lower than $0.5 \%$ and $4 \%$, for macroelements and microelements, respectively.

\subsection{Statistical analysis}

Data of all measurements were obtained in triplicate and expressed as the mean values. Statistical analyses were performed using statistical programs MS Excel (Microsoft Office 2007 Professional), Statistica v. 8 (Statsoft Inc. Tulsa, Oklahoma, USA) and NCSS software package (www.ncss.com). One-way analysis of variance (ANOVA) was used to evaluate the experimental data. Significant differences $(p \leq 0.05)$ between the mean values were detected applying Tukey's test. Principal Component Analysis was realized by PLS_Tool Box software package for MATLAB (Version 7.12.0), as described in Natić et al. (2015). Previous to PCA all data were group-scaled. The singular value decomposition algorithm (SVD) and a 0.95 confidence level for $Q$ and Hotelling T2 limits for outliers were chosen.

\section{Results and discussion}

\subsection{Total phenolic content and radical-scavenging activity}

According to the results for total phenolic content and radicalscavenging activity (Table 1), no noticeable difference among investigated grapevine leaf samples is observed. The highest TPC was identified in 'Cabernet Franc' leaf extract (76.0 g GAE/kg DW). This sample also showed the most effective DPPH radical scavenger activity ( $0.867 \mathrm{mmol} \mathrm{TE} / \mathrm{kg} \mathrm{DW})$. The lowest values for TPC and RSA were obtained in the sample of 'Pinot Gris' (27.5 g GAE/kg DW and $0.429 \mathrm{mmol} \mathrm{TE} / \mathrm{kg} \mathrm{DW}$, respectively). The results obtained for the radical scavenging activity were compared with the content of total phenolics and statistically strong linear relationship was found between them $(r=0.92, P<0.0001)$. The results of TPC for 'Merlot', 'Shiraz', and 'Vranac' obtained herein are in agreement with those reported in a previous publication (Katalinić et al., 2013).

\subsection{Phenolic profile}

Compounds were separated, and determination and quantification were done using LC MS. A total of 20 polyphenols were quantified using the available standards in the grapevine leaf extracts, mainly phenolic acids, flavan-3-ols and flavonols (Table 1). The list of quantified compounds together with mass spectrometry data and limits of detection (LOD) and quantification (LOQ) was presented in Table S1. UV chromatogram of investigated standards at $280 \mathrm{~nm}$ is shown in Fig. S1.

The study reported herein showed that leaves accumulated large amounts of phenolic acids, with especially high content of ellagic acid, in the amounts up to $770 \mathrm{mg} / \mathrm{kg}$ DW. Ellagic acid is one of the most interesting components among non-flavonoids, as it is considered as a powerful bioactive compound which exhibits a wide range of biological activities and potentially beneficial effects on human health. Previously, we have reported a comprehensive literature survey on natural sources of ellagic acid (Natić et al., 2016), which led us to a scarce number of publications concerning grapevine leaves. Among the species examined in this research, the highest amount was found in Gamay (770 mg/kg DW), followed by 'Riesling' (671 mg/kg DW), while the lowest content of ellagic acid was determined in 'Shiraz' (57.4 mg/ $\mathrm{kg}$ DW).

As for the other hydroxybenzoic acids, high content of $p$-hydroxybenzoic acid was found in some extracts (up to $151 \mathrm{mg} / \mathrm{kg} \mathrm{DW}$ in 'Muscat Hamburg'). Gallic, protocatechuic, and gentisic acids were found in lower quantities. Ferulic acid was the most abundant hydroxycinnamic acid, with the contents ranging from $7.10 \mathrm{mg} / \mathrm{kg}$ DW in 'Welschriesling' to $89.8 \mathrm{mg} / \mathrm{kg}$ DW in 'Petra'.

All cultivars were rich in rutin (content was up to $450 \mathrm{mg} / \mathrm{kg}$ in 'Petra'), which is in accordance with the data previously reported (Farhadi et al., 2016; Katalinić et al., 2009). Quercetin was found in the range from $5.65 \mathrm{mg} / \mathrm{kg}$ ('Gamay') to $52.0 \mathrm{mg} / \mathrm{kg}$ ('Beogradska besemena'). The presence of kaempferol was not detected in two samples 
('Pinot Gris' and 'Vranac'), while its concentration in other samples goes up to $19.4 \mathrm{mg} / \mathrm{kg}$ DW ('Petra').

Differences in the profile of flavan-3-ols extracted from the leaves were noticed. Especially this was observed in the case of catechin, gallocatechin and epigallocatechin (contents were in the range 1.25$60.5 \mathrm{mg} / \mathrm{kg} \mathrm{DW}, 0.00-102 \mathrm{mg} / \mathrm{kg} \mathrm{DW}$, and $1.48-66.3 \mathrm{mg} / \mathrm{kg} \mathrm{DW}$, respectively).

Grapevine leaves 'Petra' were characterized with the highest contents of protocatechuic, gentisic, caffeic, $p$-coumaric, and ferulic acids (10.5 mg/kgDW, $8.85 \mathrm{mg} / \mathrm{kg}$ DW, $19.6 \mathrm{mg} / \mathrm{kg} \mathrm{DW}, 8.17 \mathrm{mg} / \mathrm{kg} \mathrm{DW}$, and $89.8 \mathrm{mg} / \mathrm{kg}$ DW, respectively), as well as flavonols kaempferol (19.4 mg/kg DW) and rutin (450.4 mg/kg DW). Resveratrol (117 mg/ $\mathrm{kg}$ DW) was also found in the highest amount in 'Petra'.

According to results published elsewhere (Schoedl et al., 2011) 'Riesling' grapevine leaves contain higher concentrations of investigated polyphenols than leaves from 'Pinot Noir'. Our results showed the same tendency when it comes to quercetin, kaemferol, catechin, and resveratrol. We found detectable amounts of caffeic, $p$-coumaric, and ferulic acids, as well as resveratrol in the leaf samples "Pinot Noir", which was contrary to previous results (Schoedl et al., 2012).

Another objective of this work was to investigate the relationship among individual polyphenols, TPC, and RSA values.Two correlation matrixes were produced using Pearson correlation coefficient. Data are presented in Tables S1 and S2 as Supplementary material. First correlation matrix was constructed in order to define significant correlations for the studied leaves originating from Belgrade vineyard area (Table S2). All phenolic acids, except ellagic acid and chlorogenic acid, showed some significant relationships $(r>0.64, P<0.01)$. Among flavonoids, kaemferol, rutin, and resveratrol demonstrated statistically significant dependences $(r>0.67, P<0.01)$ with other phenolics. Aesculin was the only quantified phenolic compound that showed significant correlation with RSA $(r=0.66, P<0.01)$. A strong negative correlation between catechin and $p$-hydroxybenzoic acid $(r=-0.79, P<0.001)$ in the samples from Belgrade vineyard area was also observed.

As for the Mlava vineyard area, protocatehuic acid and kaempferol could be considered as major factors that influenced the antioxidant potential of the extracts, which was based on the statistically significant correlations (Table S3, $r>0.83, P<0.05$ and $r>0.78, P<0.05$, respectively). A strong positive correlations were found between the contents of kaempferol and protocatechuic acid $(r=0.90)$, epigallocatechin and catechin $(r=0.89)$, and rutin and resveratrol $(r=0.88)$, all $P<0.01$. From Table S3 one can observe several strong negative correlations with $P<0.05$.

\subsection{Minerals in grapevine leaves}

Twenty-three elements that were analyzed in the leaves are presented in Table S4. The most common element in all samples was found to be potassium, with content ranging from $2.30 \mathrm{~g} / \mathrm{kg}$ DW (in 'Welschriesling') to $6.77 \mathrm{~g} / \mathrm{kg}$ DW (in 'Muscat Hamburg'). The abundance of $\mathrm{K}$ is expected, considering that this element is essential for the growth and development of plants. Remarkable contents were also observed for B, Ca, Na, Mg, and S in all samples. Toxic elements (As, Cd and $\mathrm{Pb}$ ) were found in small amounts $0.0562-0.460 \mu \mathrm{g} / \mathrm{kg} \mathrm{DW}$, 9.40-29.4 $\mu \mathrm{g} / \mathrm{kg}$ DW, and 0.463-2.23 $\mu \mathrm{g} / \mathrm{kg} \mathrm{DW}$, respectively.

Box plots of concentrations of the various elements in leaf samples are shown in Fig. 1A and B. Square within the box indicates a median value, while the horizontal lines in the boxes represent 25 and $75 \%$ of values (error bars indicate non-outlier max and min of these values). When the median values of the element contents in analyzed leaf samples were compared, general conclusion was that the leaves of Belgrade vineyard area were richer in $\mathrm{Ca}, \mathrm{B}, \mathrm{Mg}, \mathrm{S}, \mathrm{P}, \mathrm{Al}, \mathrm{Cu}, \mathrm{Fe}, \mathrm{Cr}, \mathrm{Pb}$, and $\mathrm{V}$, while the leaves from Mlava vineyard area were characterized with higher quantities of $\mathrm{K}, \mathrm{Na}, \mathrm{Mn}, \mathrm{Mo}, \mathrm{Li}$, and $\mathrm{Ni}$. In both sets of leaves the median levels of $\mathrm{Cd}, \mathrm{Zn}, \mathrm{As}$, $\mathrm{Co}, \mathrm{Sb}$, and Se were similar
(Table S4).

Mineral characteristics of the leaves were further analyzed by correlation analyses in order to show possible interrelations among various factors that could influence the element composition. The Pearson correlation matrix constructed on element concentrations of Belgrade vineyard area and Mlava vineyard area grapevine leaves, separately, revealed some similar behavior between elements. Statistically significant dependencies are highlighted in Tables S5 and S6, for leaves belonging to Belgrade and Mlava vineyards, respectively. Significant positive correlations were observed among the Al, Fe, V and $\mathrm{Cr}$ in both sets of leaves. These correlations could indicate that the soil content of these metals contributes to their quantities in leaves since these metals are often correlated with each other in soil samples. It is known that the $\mathrm{Cr}$ content in plants is mainly controlled by the soluble $\mathrm{Cr}$ content of the soils, while the synergistic interactions between $\mathrm{Cr}$ and $\mathrm{Fe}$ are also observed (Kabata-Pendias, 2011).

Boron is relatively immobile in plants and plays an important role in translocation of sugars and adequate B supply is necessary for sugar synthesis. The main role for absorption of $B$ is passive sorption of a complex between boric acid and polysaccharides (Kabata-Pendias, 2011). The average value of B in Belgrade vineyard grapevine leaves was around $25 \mathrm{mg} / \mathrm{kg}$, while in leaves from Mlava this value was $13 \mathrm{mg} / \mathrm{kg}$ with the higher B contents compared to other micronutrients in analyzed leaves. From the correlation results it can be noticed that for leaves from Mlava vineyard area the quantities of B were positively correlated with $\mathrm{Al}, \mathrm{Fe}, \mathrm{As}, \mathrm{Cr}$, and V (Table S6). On the other hand, content of B in leaves of Belgrade vineyard area showed no correlations with other determined elements.

The element that is a negatively correlated with $\mathrm{P}, \mathrm{S}, \mathrm{Cu}, \mathrm{Fe}$, and $\mathrm{As}$ in leaves of grapevine from Mlava vineyard area was Mo (Table S6). Antagonism between $\mathrm{Mo}$ and $\mathrm{Cu}$ in plants is strongly related to $\mathrm{N}$ metabolismMo (Kabata-Pendias, 2011) and the important function of Mo in plants is nitrate reduction (Kaiser et al., 2005). In the case of Mo and Fe interactions, the low Mo availability is in soils rich in Fe, while increased Mo levels may induce Fe deficiency. An interaction between Mo and $\mathrm{P}$ is often demonstrated as an enhancing effect of $\mathrm{P}$ on Mo availability in acid soils, apparently due to the higher solubility of the phosphomolybdate complex, as well as to a higher Mo mobility within plant tissues. The interaction between Mo and $\mathrm{P}$ is complex and influenced by diverse soil factors and plant metabolic processes (Kabata-Pendias, 2011).

Although the average quantity of Cd among the analyzed leaves is similar (Table S5 and S6) this metal in leaves from Mlava vineyard area showed the positive correlations with $\mathrm{K}$ and $\mathrm{Mn}$ which is not the case for Belgrade vineyard area leaves. The average quantities of $\mathrm{K}$ and $\mathrm{Mn}$ in leaves from Mlava vineyard area were higher than in leaves from Belgrade vineyard area $\left(P<0.000001 ; F=64.64 ; F_{\text {crit }}=4.35\right.$ and $P<0.001 ; F=19.97 ; F_{\text {crit }}=4.35$, respectively) and according to previous results ${ }^{11}$ the usage of fertilizers with high $\mathrm{K}$ contents positively affected the phenolic content in L. Pumila, which could be the case in the vineyard of Mlava vineyard area.

Lead was a metal that showed negative correlations with some of elements in investigated leaves (Tables S5 and S6). A significant quantity of $\mathrm{Pb}$ in plants could have an atmospheric origin (KabataPendias, 2011; Musielińska et al., 2016), while another source is a soil. Although the most of the $\mathrm{Pb}$ pollution can be removed from the leaf surfaces by washing with detergents, there is likely to be a significant translocation of $\mathrm{Pb}$ into plant tissues. Negative correlation between $\mathrm{Pb}$ and $\mathrm{Zn}$ indicates the antagonism that adversely affects theirs translocation from roots to tops (Kabata-Pendias, 2011).

\subsection{Principal component analysis}

Twenty-two grapevine leaf samples belonging to two relatively close vine-growing areas were studied in this work. Both white grapevine leaves and black grapevine leaves of different varietal origin were 

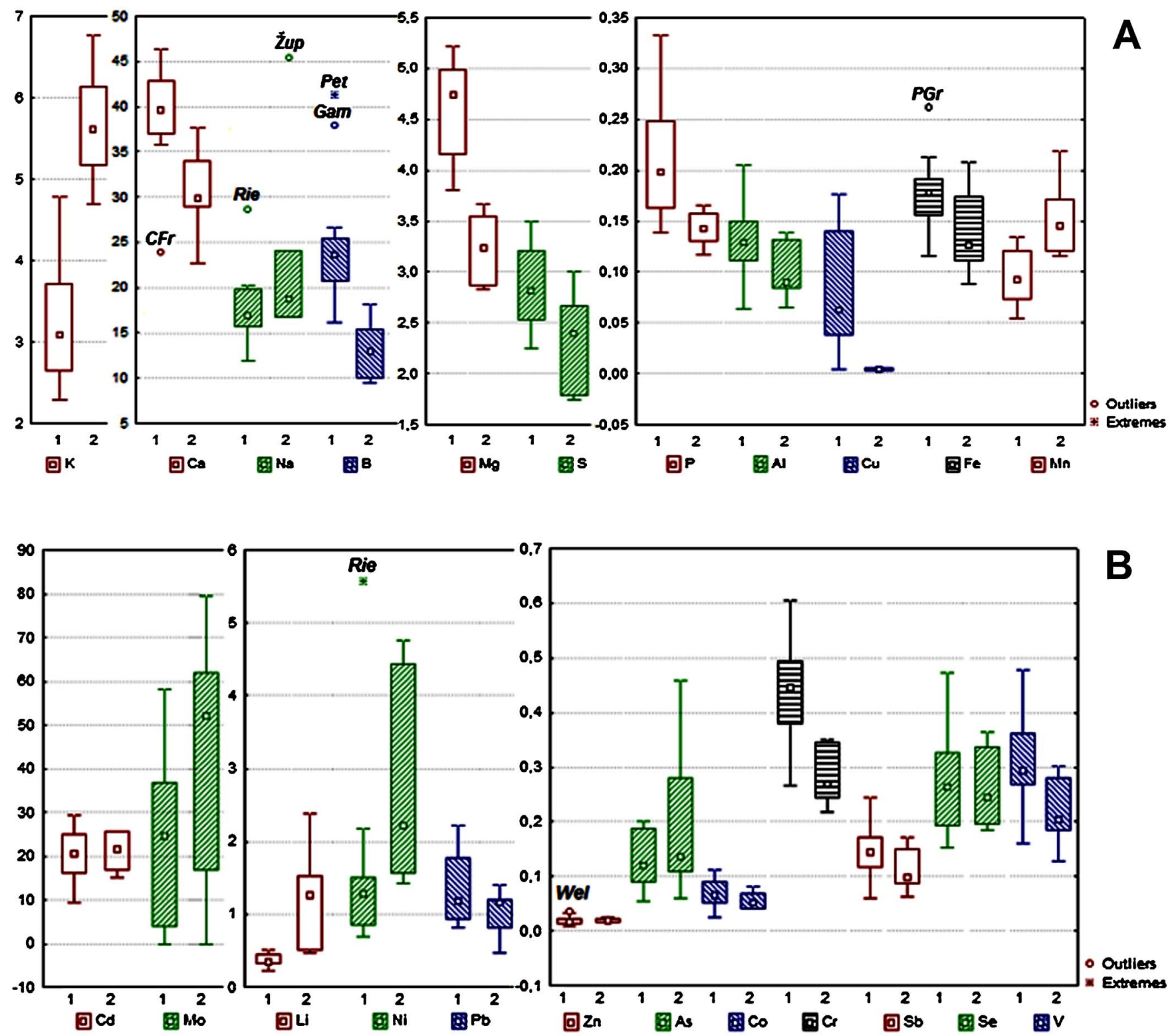

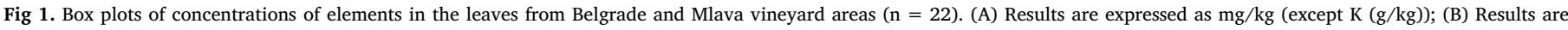
expressed as $\mu \mathrm{g} / \mathrm{kg}$.

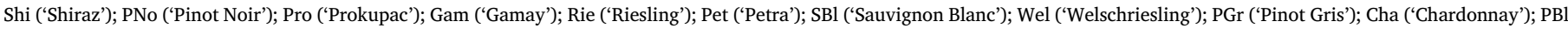
('Pinot Blank'); Vra ('Vranac'); MHa ('Muscat Hamburg'); Plo ('Plovdina'); Žup ('Župljanka'); Cmu ('Chasselas musque'); Bbe ('Beogradska besemena'); Sme ('Smederevka').

collected. Due to diversity of the tested samples, two pivotal questions arise: Is it possible to distinguish among two regions based on the content of minerals and phenolics? Whether two separate clusters will be formed based on the colour of grapes? Therefore, to look over closely for trends, groupings and outliers among leaves tested, Principal Component Analysis was employed.

Published results indicated the strong impact of mineral content in determining geographical origin (Fernández-Cáceres et al., 2001; Versari et al., 2014). Also, some evidence on the impact of polyphenols exists in literature (Garrido and Borges, 2013). TPC, RSA, the content of each determined polyphenol and each mineral served as input data. The initial matrix 22 (the number of leaf samples) $\times 45$ (quantified phenolics, minerals, TPC, and RSA) was processed using the covariance matrix with standardization. The PCA resulted in an eight-component model that explained $81.53 \%$ of the total variance (Fig. 2A). The first principal component accounted for $25.70 \%$, the second $13.60 \%$ and the third component $13.32 \%$ of the total variance. The most influential variables responsible for the possible grouping of the grape leaves were identified using the loading plots (Fig. 2B).

As expected, the PCA score plots showed the presence of the two main groups of grape leaves separated according to geographical origin along the PC1 axis. Extracts were associated among themselves according to their characteristic chemical profiles, mostly based on several minerals and few individual flavonoids and phenolic acids. Leaves from Belgrade vineyard area were characterized with higher contents of minerals $\mathrm{Cr}, \mathrm{V}, \mathrm{Fe}, \mathrm{Al}$, and $\mathrm{Mg}$, and polyphenol catechin. Phenolic acids (gallic acid, $p$-hydroxybenzoic acid, and ferulic acid) and minerals (K, Mn, and $\mathrm{Li}$ ) were the most influential variables responsible for the separation of leaves from Mlava vineyard area. Based on the PCA score plot leaf sample 'Petra' can be considered as an outlier (lying outside the Hotteling T2 ellipse). This interspecies hybrid is characterized with higher contents of kaempferol and three hydroxycinnamic acids (caffeic acid, $p$-coumaric acid, and ferulic acid) when compared to the rest of the samples. 'Petra' is also rich in resveratrol, which could be interpreted by its reduced susceptibility to Botrytis cinerea P. and Plasmopara viticola (Cindrić et al., 2000). 

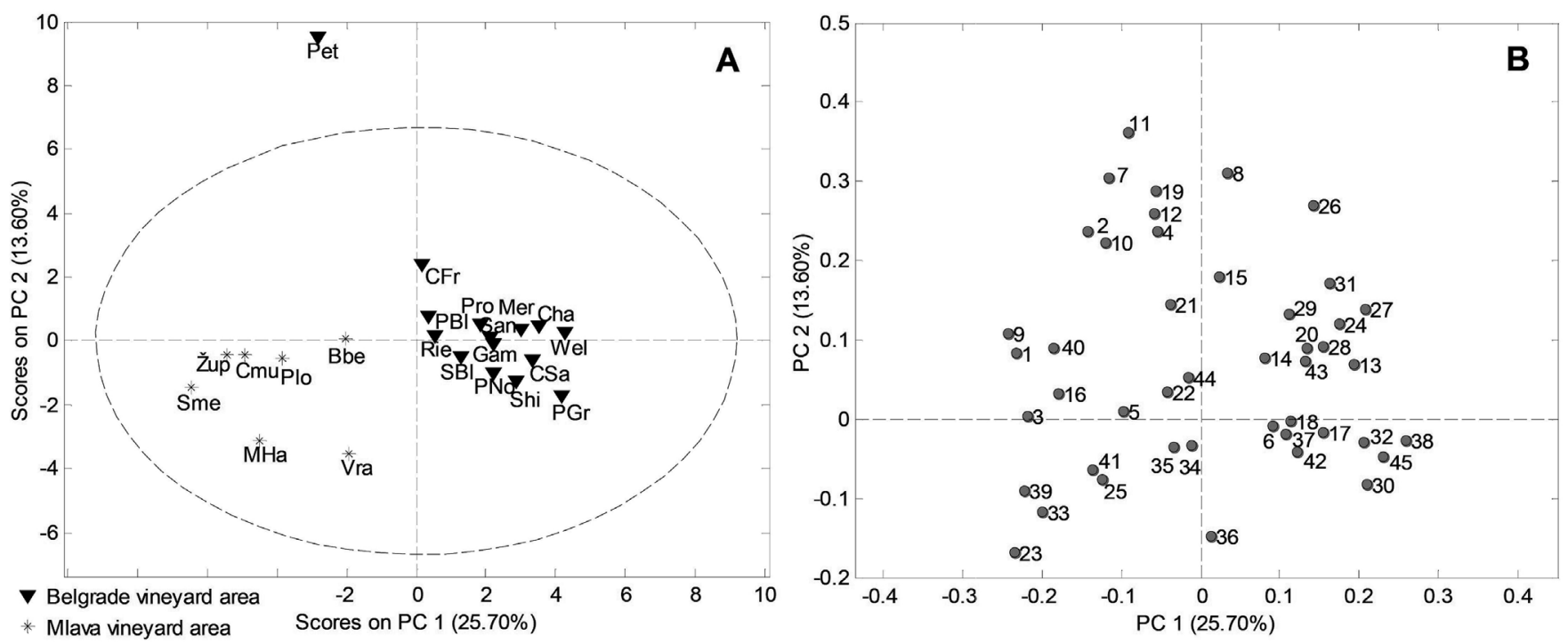

Fig. 2. Principal Component Analysis. (A) Scores plot showing the sample clustering; (B) Loadings plot reflecting the influence of a particular parameter.

From the PCA analysis, it can be seen that the Cd is located close to gallic acid and epigallocatechin gallate in leaves from the Mlava vineyard area. Based on previous work (Márquez-García et al., 2012), cadmium increases the total levels of phenolic compounds and the total antioxidant capacity also. Such findings support the idea that polyphenols could be considered as potential biomarkers of pollution (Białońska et al., 2007). Higher content of polyphenols in plants is believed to be in relation to their role in plant's response to heavy metal accumulation, where these compound act as scavengers of free radicals.

\section{Conclusions}

This research deals with constitutive phenolics and minerals in grape leaves of diverse varietal origin collected from two locations in Serbia. The study was designed to show whether chemical composition could be utilized to distinguish among the samples. Although samples originate from two relatively close regions, our results showed that certain conclusions regarding the geographical origin could be drawn. Such a grouping could be ascribed to differences in growing and cultivation conditions in two established vineyards.

Also, it was shown that variation in the content of individual compounds could rise due to differences based on variety. Subgroups were visible on the PCA score plots indicating possible grouping of white and black grapevine leaves. This could be linked to the existence of complex chemical interactions that can occur between minerals and polyphenols. Also, different capacity of the cultivars to absorb metal ions from soils and specific distribution within the overall plant could be the reason for distinguishing among varieties. Finally, this research could be considered as important in terms of potency of grapevine leaves extracts as a good source of natural antioxidants. Due to high nutritional value and especially high content of ellagic acid, grapevine leaves can be used in traditional recipes or for the preparation of the extracts that can be used as supplements in food and medicines. However, one should always keep on mind possible effects of hazardous substances on occupational health and safety, especially when toxic elements are to be considered.

\section{Acknowledgements}

This work was performed within the framework of the research projects No. 172017 and No. 43007, supported by the Ministry of Education, Science and Technological Development, Republic of Serbia. The authors are grateful to Mrs Sonja Jović for providing the leaf samples.

\section{Appendix A. Supplementary data}

Supplementary data associated with this article can be found, in the online version, at http://dx.doi.org/10.1016/j.jfca.2017.05.002.

\section{References}

Bertacchini, L., Cocchi, M., Vigni, M.L., Marchetti, A., Salvatore, E., Sighinolfi, S., Silvestri, M., Durante, C., 2013. The impact of chemometrics on food traceability. Chemom. Food Chem. 28, 371-410.

Białońska, D., Zobel, A.M., Kuraś, M., Tykarska, T., Sawicka-Kapusta, K., 2007. Phenolic compounds and cell structure in bilberry leaves affected by emissions from a $\mathrm{Zn}-\mathrm{Pb}$ smelter. Water Air Soil Pollut. 181, 123-133.

Cacciola, F., Farnetti, S., Dugo, P., Marriott, P.J., Mondello, L., 2016. Comprehensive twodimensional liquid chromatography for polyphenol analysis in food stuffs. J. Sep. Sci. 00, 1-18.

Cindrić, P., Korać, N., Kovač, V., 2000. Grape breeding in the Vojvodina province. Acta Hortic. 528, 505-510.

Cugnetto, A., Santagostini, L., Rolle, L., Guidoni, S., Gerbi, V., Novello, V., 2014. Tracing the terroirs via the elemental composition of leaves, grapes and derived wines in cv Nebbiolo (Vitis vinifera L.). Sci. Hort. 172, 101-108.

Dani, C., Oliboni, L.S., Agostini, F., Funchal, C., Serafini, L., Henriques, J.A., Salvador, M., 2010. Phenolic content of grapevine leaves (Vitis labrusca var: Bordo) and its neuroprotective effect against peroxide damage. Toxicol. In Vitro 24, 148-153.

Donno, D., Boggia, R., Zunin, P., Cerutti, A.K., Guido, M., Mellano, M.G., Prgomet, Z., Beccaro, G.L., 2015. Phytochemical fingerprint and chemometrics for natural food preparation pattern recognition: an innovative technique in food supplement quality control. J. Food Sci. Technol. 53, 1071-1083.

Donno, D., Beccaro, G.L., Carlen, C., Ancay, A., Cerutti, A.K., Mellano, M.G., Bounous, G. 2016. Analytical fingerprint and chemometrics as phytochemical composition control tools in food supplement analysis: characterization of raspberry bud-preparations of different cultivars. J. Sci. Food Agric. 96, 3157-3168.

Farhadi, K., Esmaeilzadeh, F., Hatami, M., Forough, M., Molaie, R., 2016. Determination of phenolic compounds content and antioxidant activity in skin, pulp, seed, cane and leaf of five native grape cultivars in West Azerbaijan province, Iran. Food Chem. 199, $847-855$.

Fernández-Cáceres, P.L., Martín, M.J., Pablos, F., González, G.A., 2001. Differentiation of tea (Camellia sinensis) varieties and their geographical origin according to their metal content. J. Agric. Food. Chem. 49, 4775-4779.

Garrido, J., Borges, F., 2013. Wine and grape polyphenols-A chemical perspective. Food Res. Int. 54, 1844-1858.

Gioxari, A., Kogiannou, D.A.A., Kalogeropoulos, N., Kaliora, A.C., 2016. Phenolic compounds: bioavailability and health effects. In: In: Caballero, B., Finglas, P.M., Toldrá, F. (Eds.), Encyclopedia of Food and Health Vol. 1. Elsevier Science, Kidlington, United Kingdom, UK, pp. 339-345.

Handoussa, H., Hanafi, R., Eddiasty, I., El-Gendy, M., El Khatib, A., Linscheid, M., Mahran, L., Ayoub, N., 2013. Anti-inflammatory and cytotoxic activities of dietary phenolics isolated from Corchorus olitorius and Vitis vinifera. J. Funct. Foods 5, 1204-1216.

Ibrahim, M.H., Jaafar, H.Z.E., Karimi, E., Ghasemzadeh, A., 2012. Primary, secondary metabolites: photosynthetic capacity and antioxidant activity of the Malaysian Herb Kacip Fatimah (Labisia Pumila Benth) exposed to potassium fertilization under 
greenhouse conditions. Int. J. Mol. Sci. 13, 15321-15342.

Kabata-Pendias, A., 2011. Trace Elements in Soils and Plants. CRC Press, New York, USA. Kaiser, B.N., Gridley, K.L., Ngaire Brady, J., Phillips, T., Tyerman, S.D., 2005. The role of molybdenum in agricultural plant production. Ann. Bot. 96, 745-754.

Katalinić, V., Generalić, I., Skroza, D., Ljubenkov, I., Teskera, A., Konta, I., Boban, M., 2009. Insight in the phenolic composition and antioxidative properties of Vitis vinifera leaves extracts. Croatian J. Food Sci. Technol. 1, 7-15.

Katalinić, V., Smole Mozina, S., Generalić, I., Skroza, D., Ljubenkov, I., Klančnik, A., 2013. Phenolic profile, antioxidant capacity, and antimicrobial activity of leaf extracts from six Vitis vinifera L. varieties. Int. J. Food Prop. 16, 45-60.

Kottek, M., Grieser, J., Beck, C., Rudolf, B., Rubel, F., 2006. World map of the KöppenGeiger climate classification updated. Meteorol. Z. 15, 259-263.

Krol, A., Amarowicz, R., Weidner, S., 2014. Changes in the composition of phenolic compounds and antioxidant properties of grapevine roots and leaves (Vitis vinifera L.) under continuous of long-term drought stress. Acta Physiol. Plant. 36, 1491-1499.

Likar, M., Vogel-Mikuš, K., Potisek, M., Hančević, K., Radić, T., Nečemer, M., Regvar, M., 2015. Importance of soil and vineyard management in the determination of grapevine mineral composition. Sci. Total Environ. 505, 724-731.

Márquez-García, B., Fernández-Recamales, M.A., Córdoba, F., 2012. Effects of cadmium on phenolic composition and antioxidant activities of Erica andevalensis. J. Bot. 2012, 936950.

Musielińska, R., Kowol, J., Kwapuliński, J., Roche, R., 2016. Antagonism between lead and zinc ions in plants. Arch. Environ. Prot. 42, 78-91.

Natić, M., Dabić, D., Papetti, A., Akšić, Fotirić, Ognjanov, M., Ljubojević, V., Tešić, M. 2015. Analysis and characterisation of phytochemicals in mulberry (Morus alba L.) fruits grown in Vojvodina, North Serbia. Food Chem. 171, 128-136.
Natić, M., Dabić Zagorac, D., Gašić, U., 2016. Extraction and analysis of ellagic acid and ellagitannins from various food sources. In: Brewer, E. (Ed.), Ellagic Acid: Food Sources, Potential Role in Human Health and Antioxidant Effects. Nova Science Publishers Inc, New York, NY, USA, pp. 1-50.

Pantelić, M., Dabić Zagorac, D., Natić, M., Gašić, U., Jović, S., Vujović, D., Popović Djordjević, J., 2016. Impact of clonal variability on phenolics and radical scavenging activity of grapes and wines: a study on the recently developed Merlot and Cabernet Franc clones (Vitis vinifera L.). PLoS One 11, e0163823.

Schoedl, K., Forneck, A., Sulyok, M., Schuhmacher, R., 2011. Optimization, in-house validation, and application of a liquid chromatography-tandem mass spectrometry (LC-MS/MS)-based method for the quantification of selected polyphenolic compounds in leaves of grapevine (Vitis vinifera L.). J. Agric. Food. Chem. 59, 10787-10794.

Schoedl, K., Schuhmacher, R., Forneck, A., 2012. Studying the polyphenols of grapevine leaves according to age and insertion level under controlled conditions. Sci. Hort. 141, 37-41.

Stalikas, C., 2007. Extraction, separation: and detection methods for phenolic acids and flavonoids. J. Sep. Sci. 30, 3268-3295.

Taware, P.B., Dhumal, K.N., Oulkar, D.P., Patil, S.H., Banerjee, K., 2010. Phenolic alterations in grape leaves: berries and wines due to foliar and cluster powdery mildew infections. Int. J. Pharma Bio Sci. 1, 1-14.

Teixeira, A., Eiras-Dias, J., Castellarin, S.D., Gerós, H., 2013. Berry phenolics of grapevine under challenging environments. Int. J. Mol. Sci. 14, 18711-18739.

Versari, A., Laurie, V.F., Ricci, A., Laghi, L., Parpinello, G.P., 2014. Progress in authentication: typification and traceability of grapes and wines by chemometric approaches. Food Res. Int. 60, 2-18. 